\title{
Comparison of gastrointestinal symptoms in colorectal carcinoma patients and community controls with respect to age
}

\author{
R Curless, J French, G V Williams, O F W James
}

\begin{abstract}
Early diagnosis of colorectal cancer may be delayed by the wide prevalence of gastrointestinal symptoms in the general population. This study assessed, with respect to age, the frequency of gastrointestinal symptoms in patients with colorectal carcinoma in comparison with community controls and also compared the frequency of such symptoms between 'young' (under 70 years) and 'old' (70 year or over) subjects. Two hundred and seventy three consecutive unselected colorectal cancer patients and 273 age and sex matched community controls were interviewed in a structured manner. Among controls, the 'old' group compared with the 'young' reported abdominal pain $(p<0 \cdot 05)$, mucous discharge $(p<0.01)$, faecal incontinence $(\mathbf{p}<0.05)$, change in flatus production $(p<0.05)$ significantly more often. There were no significant differences in regularity and frequency of bowel habit by age group. All the symptoms considered were significantly more common in colorectal cancer cases than controls (except abdominal bloating), but the association was less strong in the 'old' group. This study confirms that symptoms attributable to the lower gastrointestinal tract are reported by a clinically important number of community subjects and by a significantly higher proportion of elderly people. (Gut 1994; 35: 1267-1270)
\end{abstract}

Gastrointestinal symptoms are widely prevalent in the general population, ${ }^{12}$ thus leading to difficulty in the diagnosis of specific disease. Although there is an increasing amount of published reports examining symptom complexes such as dyspepsia ${ }^{34}$ and the irritable bowel syndrome, ${ }^{56}$ less attention has been paid to gastrointestinal symptoms in older people where serious organic abnormality is more prevalent. Subjective constipation, for example, is widely held to be more common in the elderly, with estimates of self reported constipation varying from 23 to $34 \% .{ }^{78}$ Actual frequency of defecation less than thrice weekly, however, was found in only $2 \%$ of men and $7 \%$ of women aged $62-90.9$ Other lower gastrointestinal symptoms are less well reported in the elderly.

Colorectal carcinoma, the second commonest malignancy in the United Kingdom, is predominantly a disease of advancing age with the risk of developing the condition doubling with each decade. ${ }^{1011}$ Overall survival at five years is no better than $40 \%$ principally because of the advanced stage of disease at presentation $^{12}$ and substantial numbers of patients still present as emergencies with an associated increased in hospital mortality. ${ }^{13}$ There may be considerable delay from symptom onset to treatment, previously estimated as 7.5 and 9 months for colonic and rectal cancer respectively. ${ }^{14}$ Despite recent data showing decreased delay, ${ }^{15}$ it remains unclear whether such decrements will have any effect on overall survival rates. ${ }^{16} 17$ It is possible that the delay in diagnosis and treatment is a consequence of the common occurrence of colorectal symptoms in the general population: $47 \%$ and $27 \%$ of women and men respectively aged $25-69,{ }^{18}$ thus leading subjects to ignore early symptoms that may point to the presence of carcinoma.

Information about the frequency of lower bowel symptoms in those aged 70 years or more is sparse. We hypothesised that such symptoms may be more common in the 'healthy' old than the 'healthy' young. Furthermore, we speculated that this might lead to a loss of symptom specificity for serious organic disease (such as colorectal cancer) in the elderly.

The aims of this study, therefore, were to assess with respect to age, the frequency of gastrointestinal symptoms in patients with colorectal carcinoma in comparison with community controls, and to compare the frequency of these symptoms between 'young' (under age 70 years) and 'old' (70 years or over) community controls and 'young' and 'old' patients presenting with colorectal cancer.

\section{Methods}

\section{SUBJECTS}

\section{Colorectal cancer cases}

Consecutive unselected patients with a histological diagnosis of colorectal adenocarcinoma who presented to the hospitals of Gateshead and Newcastle Health Districts in the year commencing October 1989 and resident within Newcastle, Gateshead or the adjacent counties of Tyne and Wear or Northumberland were eligible for inclusion in the study. Patients were identified by daily contact with the resident surgical officers of the four participating hospitals and twice weekly 
TABLE I Demographic details of cases and controls. Age of subjects by decades of age and sex

\begin{tabular}{|c|c|c|c|c|}
\hline \multirow[b]{2}{*}{ Age } & \multicolumn{2}{|c|}{ Cases $(n=273)$} & \multicolumn{2}{|c|}{ Controls $(n=273)$} \\
\hline & Male & Female & Male & Female \\
\hline $20-29$ & 0 & 1 & 0 & 1 \\
\hline $30-39$ & 0 & 0 & 0 & 0 \\
\hline $40-49$ & 6 & 2 & 5 & 2 \\
\hline $50-59$ & 32 & 9 & 33 & 12 \\
\hline $60-69$ & 63 & 37 & 62 & 33 \\
\hline $70-79$ & 35 & 41 & 37 & 42 \\
\hline $80-89$ & 17 & 26 & 16 & 26 \\
\hline $90-99$ & - & 4 & - & 4 \\
\hline Total & 153 & 120 & 153 & 120 \\
\hline
\end{tabular}

inspection of histology records and surgical admission lists. All patients were interviewed in hospital by one observer (RC), preoperatively wherever possible, always within 14 days of histological diagnosis. Patients with a previous diagnosis of colorectal adenoma or carcinoma, known colitis, non-whites, and those dying before interview could take place were excluded.

\section{Controls}

Sex and age ( $+/-2$ years) matched unrelated controls who were adjacent on the general practitioners' age/sex register to each colorectal cancer propositus were identified. Permission to write to them was obtained from their general practitioner. Controls who consented to participate were visited at home and interviewed by the same observer (RC). If a control subject declined to participate, they could not be contacted after three visits at different times of day or the GP advised against approaching them, the next suitably matched control from the GP register was then approached. Controls were excluded if they had known colorectal adenoma, carcinoma or inflammatory bowel disease.

\section{DATA COLLECTION}

\section{Questionnaire}

A structured questionnaire was given verbally to both patients and controls by the same observer (RC) and recorded in a standard manner on a specifically designed proforma (questionnaire available from the authors). Data were collected on 21 gastrointestinal symptoms during the previous year by the use of direct closed questions. Questions were put in every day language and positive responses triggered further questions about the frequency and duration of those symptoms. All symptoms were defined in a standard manner. Data concerning the use of proprietary and non-proprietary laxatives and antacids in the preceding 12 months were recorded.

\section{DATA ANALYSIS AND STATISTICS}

Responses were coded by a standard format on a proforma especially designed for transfer to the Northumbrian University's Multiple Access Computer (NUMAC). Computer instructions were written to read raw data and create a system file using SPSSX (SPSSX
Batch system, SPSS Inc, Chicago, Illinois, USA). Verification procedures were carried out to ensure that there had been accurate transcription of the data.

Subjects were divided by age into those under 70 years ('young') and those 70 years or above ('old'). Discrete variables were analysed using the $\chi^{2}$ test with Yates's correction where appropriate. The odds ratio (OR) was also calculated as a further measure of association, ${ }^{19}$ thus symptoms with an OR greater than one were more likely to be reported by colorectal cancer cases than controls. A local programme for the calculation of odds ratios was written by JMF.

The study was approved by both Newcastle and Gateshead ethical and local medical committees.

\section{Results}

Two hundred and ninety two cases were admitted to hospital during the study period of whom 19 were excluded from the study: 12 were too ill to be interviewed upon admission and died shortly afterwards, four lived outwith the area, two refused consent, and in one patient the diagnosis was not clear until after discharge. Three hundred and thirty five potential controls were identified. A total of $81.5 \%$ of 'first choice' controls agreed to interview, 62 'first choice' controls could not be interviewed: 43 refused, six could not be contacted, six had moved outwith the area, three had died, and in four the general practitioner advised against contact. Demographic details of the cases and controls included in the analysis are presented (Table I). One hundred and twenty three cases $(45 \%)$ and 125 controls $(46 \%)$ were aged 70 years or greater and $56 \%$ were men. The median age of cases and controls was 68 years (range 25-93).

\section{COMPARISON OF BOWEL SYMPTOMS IN}

\section{COMMUNITY CONTROLS BY AGE}

Among community controls, the 'old' group $v$ the 'young' group reported abdominal pain $(>6$ episodes $)(14 \quad(11 \cdot 2 \%)$ v $6 \quad(4 \cdot 0 \%)$; $\mathrm{p}<0.05)$; mucous discharge per rectum (13 (10.4\%) v $3(2.0 \%) ; \mathrm{p}<0.01)$; faecal incontinence $(8(6.4 \%) v 0(0 \%) ; \mathrm{p}<0.05)$, and change in flatus production $(21(16.8 \%)$ v $12(8 \cdot 1 \%) ; \mathrm{p}<0.05)$, significantly more often. Furthermore, this group were also significantly more likely to respond positively to questions about change in energy (malaise), (40 (32.0\%) v $25 \quad(16.9 \%)$; $\mathrm{p}<0.05)$; appetite (anorexia) (14 (11.2\%) v 5 $(3.4 \%) ; \mathrm{p}<0.05)$, and abdominal swelling or fullness (bloating) $(28(22 \cdot 4 \%) v 17(11 \cdot 5 \%)$; $\mathrm{p}<0.05)$. The 'old' group tended to report the following symptoms more often: tenesmus (14 $(11 \cdot 2 \%)$ v $7(4 \cdot 7 \%)$; NS); change in bowel habit (4 (3.2\%) v 0 ( $0 \%)$; NS), and subjective weight loss $(14(11 \cdot 2 \%) v 8$ $(5 \cdot 4 \%)$; NS). Rectal bleeding was the only symptom less often reported by 'old' controls although this did not reach statistical 


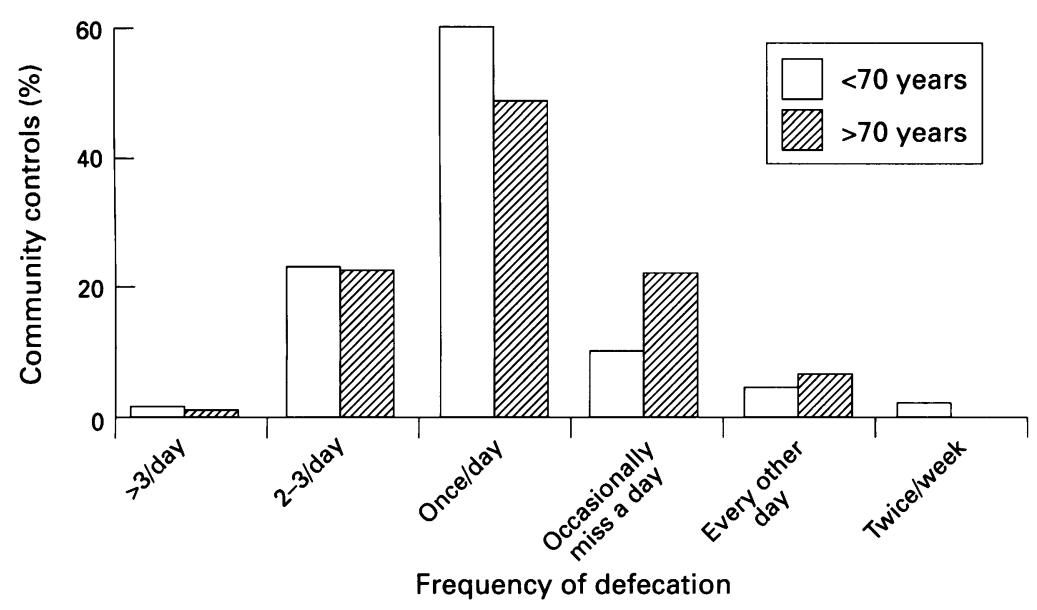

Percentage of community controls $<70$ years and $>70$ years claiming different frequencies of defecation.
COMPARISON OF GASTROINTESTINAL SYMPTOMS BETWEEN COLORECTAL CARCINOMA CASES AND COMMUNITY CONTROLS WITH RESPECT TO AGE (Table II)

The odds ratio were greater than unity for all symptoms in both age groups (except bloating in the 'old' group). In every case, however, the odds ratio for a given symptom was lower in the 'old' group than in the 'young'.

\section{Discussion}

This study confirms that symptoms attributable to the lower gastrointestinal tract may occur in a small but clinically important number of 'healthy' community subjects. Controls over 70 years were significantly more likely to report abdominal pain, mucus per rectum, faecal incontinence, change in flatus production, malaise, anorexia, and bloating within the last year. Thus, those symptoms that could point to colorectal abnormality are more often reported by supposedly healthy community dwellers in the very age group most likely to have serious disease.

The $11 \%$ reporting rate of abdominal pain ( $>6$ episodes) in those 70 years or more was lower than in a recent Danish study of a similar age group, which found rates of $28 \%$ in women and $17 \%$ in men ${ }^{20}$ and also lower than the overall rates of $25 \% \%^{2}$ and $20 \%$ of women, $10 \%$ of men ${ }^{18}$ reported in younger British populations. It is similar, however, to the $11-12 \%$ and 4-10\% proportions reported for women and men respectively by five year age bands in a larger study of over 3000 Americans greater than 65 years. ${ }^{8}$ Rates of $10 \%$ for both rectal bleeding and mucus per rectum in patients 70 years or greater, supports previous concerns about the possibility of serious undetected disease. ${ }^{21}$ Although the elderly were less likely than their younger counterparts to report rectal bleeding we believe this could reflect under reporting by this group because of visual impairment.

Constipation in older people has been

Comparison of the reported frequency of gastrointestinal symptoms within the last year by colorectal cancer cases community controls by age group ('young' <70 years; 'old' 70 years or greater). Expressed as odds ratio and $95 \%$ confidence intervals (OR:CI)

\begin{tabular}{|c|c|c|c|c|c|c|}
\hline \multirow[b]{2}{*}{ Symptom } & \multicolumn{3}{|l|}{ Young } & \multicolumn{3}{|l|}{ Old } \\
\hline & $\begin{array}{l}\text { Cases } \\
(n=150)\end{array}$ & $\begin{array}{l}\text { Controls } \\
(n=148)\end{array}$ & $O R(C I)$ & $\begin{array}{l}\text { Cases } \\
(n=123)\end{array}$ & $\begin{array}{l}\text { Controls } \\
(n=125)\end{array}$ & $O R(C I)$ \\
\hline Change in bowel habit & 111 & 0 & $\begin{array}{l}418 \cdot 4^{\star} \\
(169 \cdot 2-1034 \cdot 7)\end{array}$ & 83 & 4 & $\begin{array}{l}64 \cdot 4 \\
(30 \cdot 0-138 \cdot 4)\end{array}$ \\
\hline Abdominal pain & 81 & 6 & $\begin{array}{l}27 \cdot 9 \\
(14.0-55 \cdot 2)\end{array}$ & 59 & 14 & $\begin{array}{l}7 \cdot 3 \\
(4 \cdot 0-13 \cdot 5)\end{array}$ \\
\hline Faecal incontinence & 27 & 0 & $\begin{array}{l}32 \cdot 3^{\star} \\
(8 \cdot 5-121 \cdot 9)\end{array}$ & 23 & 8 & $\begin{array}{l}3 \cdot 4 \\
(1 \cdot 5-7 \cdot 6)\end{array}$ \\
\hline Tenesmus & 68 & 7 & $\begin{array}{l}16 \cdot 7 \\
(8 \cdot 4-33 \cdot 1)\end{array}$ & 30 & 14 & $\begin{array}{l}2 \cdot 6 \\
(1 \cdot 3-5 \cdot 2)\end{array}$ \\
\hline Mucus per rectum & 53 & 3 & 26.4 & 27 & 13 & $\begin{array}{l}2 \cdot 5 \\
(1 \cdot 2-5 \cdot 0)\end{array}$ \\
\hline Rectal bleeding & 93 & 21 & $\begin{array}{l}9.9 \\
(5 \cdot 8-16 \cdot 7)\end{array}$ & 49 & 13 & $\begin{array}{l}5 \cdot 8 \\
(3 \cdot 0-11 \cdot 0)\end{array}$ \\
\hline Change in flatus & 70 & 12 & $\begin{array}{l}9 \cdot 9 \\
(5 \cdot 4-18 \cdot 1)\end{array}$ & 39 & 21 & $\begin{array}{l}2 \cdot 4 \\
(1 \cdot 3-4 \cdot 3)\end{array}$ \\
\hline Anorexia & 52 & 5 & $\begin{array}{l}15 \cdot 2 \\
(7 \cdot 0-33 \cdot 0)\end{array}$ & 66 & 14 & $\begin{array}{l}9 \cdot 2 \\
(5 \cdot 0-16 \cdot 8)\end{array}$ \\
\hline Weight loss & 70 & 8 & $15 \cdot 3$ & 59 & 14 & $\begin{array}{l}7 \cdot 4 \\
(4 \cdot 0-13 \cdot 7)\end{array}$ \\
\hline Bloating & 68 & 17 & $6 \cdot 4$ & 38 & 28 & $\begin{array}{l}1.5 \\
(0.9-2 \cdot 7)\end{array}$ \\
\hline Malaise & 57 & 25 & $\begin{array}{l}3 \cdot 0 \\
(1 \cdot 8-5 \cdot 1)\end{array}$ & 60 & 40 & $\begin{array}{l}2 \cdot 0 \\
(1 \cdot 2-3 \cdot 4)\end{array}$ \\
\hline
\end{tabular}

$\left({ }^{\star}\right.$ Estimated OR when cell $\left.=0\right)$. 
bedevilled by problems of definition ${ }^{22}$ and recall bias. ${ }^{23}$ Furthermore, many patients who regard themselves as constipated have defecation frequencies regarded as within the normal range. ${ }^{24}$ None the less, both longitudinal ${ }^{25}$ and cross sectional ${ }^{26} 27$ studies consistently suggest that self report constipation and laxative use increase with ageing. To overcome problems of definition, we asked subjects about the regularity and frequency of defecation and about change in normal bowel habit within the last year. No age effect among elderly controls compared with their younger counterparts was detected, the distribution of defecation frequencies being very similar to that reported elsewhere. ${ }^{792427-30}$ The increased rate of laxative use reported by our elderly controls despite similar defecation frequencies is a consistent finding in published reports. ${ }^{792425} 2830$ Although this is not a prevalence study, it is reassuring that reported rates of gastrointestinal complaints are largely comparable with other series.

The main aim of this study was to compare symptoms in colorectal cancer cases to age and sex matched community controls with similar geographical and socioeconomic backgrounds. Cases and controls were well matched on these variables. Selection of a suitable control group is always problematic. Virtually all cases were interviewed in hospital and knew themselves to be suffering with a 'bowel' illness whereas controls were seen at home, which may introduce a recall bias. We elected to use community rather than hospital controls, because we felt the second group may well be suffering from other gastrointestinal diseases (for example, alcohol or drug related).

This study has shown, for both young and old age groups, significantly higher odds ratios for 10 of 11 symptoms listed (abdominal bloating is the exception) in colorectal cancer cases compared with controls. The usefulness of the odds ratio is that it gives an indication of the strength of an association in addition to its purely statistical significance, but in clinical practice a symptom with an odds ratio of say two or three is probably of less use in guiding a patient or family doctor in their consultation behaviour than one whose odds ratio is 10 or 20 . These data would suggest that the following symptoms may carry most weight in determining the odds of there being a colorectal cancer in subjects over 70 years: change in bowel habit, anorexia, weight loss, abdominal pain, rectal bleeding. The other symptoms with odds ratios of between two and three are much less likely to be discriminatory. Furthermore, for each symptom listed the size of the odds ratio for the young and old groups is smaller in the second group, emphasising the enhanced difficulty in using symptoms to guide diagnosis in patients over 70 years. It is unclear to what extent such difficulties lead to the excess delay in diagnosis in elderly patients reported in some ${ }^{31}$ but not all studies. ${ }^{32} 33$

1 Jones R, Lydeard S. Prevalence of symptoms of dyspepsia in the community. BMF 1989; 298: 30-2.

2 Jones $R$, Lydeard $S$. Irritable bowel syndrome in the general population. BMF 1992; 304: 87-90.

3 Barbara L, Camilleri M, Corinaldesi R, et al. Definition and investigation of dyspepsia. Consensus of an international ad hoc working party. Dig Dis Sci 1989; 34: 1272-6.

4 Talley NJ, McNeil D, Piper DW. Discriminant value of dyspeptic symptoms: a study of the clinical presentation of 221 patients with dyspepsia of unknown cause, peptic ulceration and cholelithiasis. Gut 1987; 28: 40-6.

5 Talley NJ, Phillips SF, Melton LJ, et al. Diagnostic value of the Manning criteria in irritable bowel syndrome. Gut 1990; 31: 77-81.

6 Manning AP, Thompson WG, Heaton KW, et al. Towards positive diagnosis of the irritable bowel. $B M F$ 1978; ii: 653-4.

7 Donald IP, Smith RG, Cruikshank JG, et al. A study of constipation in the elderly living at home. Gerontology 1985; 31: 112-8.

8 Hale WE, Perkins LL, May FE, et al. Symptom prevalence in the elderly: an evaluation of age, sex, disease and medication use. $\mathcal{F}$ Am Geriatr Soc 1986; 34: 333-40.

9 Milne JS, Williamson J. Bowel habit in older people. Geronterol Clin 1972; 14: 56-60.

10 OPCS. Mortality statistics. Series DH2 no 17 1990. London: HMSO, 1991.

11 OPCS. Monitor 1986. Cancer survival 1979-1981 registrations series. MBI 86/2. London: HMSO.

12 Stower MJ, Hardcastle JD. The results of 1115 patients with colorectal cancer treated over an 8 year period in a wingle hospital. Eur $\mathcal{F}$ Surg Oncol 1985; 11: 119-23.

13 Waldron RP, Donovan IA, Drumm J, et al. Emergency presentation and mortality from colorectal cancer in the presentation and mortality from color

14 Holliday HW, Hardcastle JD. Delay in diagnosis and treatment of symptomatic colorectal cancer. Lancet 1979; i: $309-11$

15 Dixon AR, Thornton-Holmes J, Cheetham NM. General practitioners' awareness of colorectal cancer: a 10 year review. $B M F$ 1990; 301: 152-3.

16 Barillari P, de Angelis R, Valabrega S, et al. Relationship of symptom duration and survival in patients with colorectal carcinoma. Eur f Surg Oncol 1989; 45: 225-30.

17 Robinson E, Mohilever J, Zidan J, et al. Colorectal cancer: incidence, delay in diagnosis and stage of disease. Eur f Cancer Clin Oncol 1986; 22: 157-61.

18 Heaton KW, O'Donnell LJD, Braddon FE, et al. Symptoms of irritable bowel syndrome in a British urban community: consulters and

19 Sandercock $P$. The odds ratio: a useful tool in neurosciences. f Neurol Neurosurg Psychiatry 1989; 52: 817-20.

20 Kay L, Jorgensen T, Schultz-Larsen K. Abdominal pain in a 70 year old Danish population. $\mathcal{f}$ Clin Epidemiol 1992; 45: $1377-82$.

21 MacDonald L, Freeling P. Bowels: beliefs and behaviour. Family Practice 1986; 3: 80-4.

22 Moore-Gillon V. Constipation: what does the patient mean? $\mathcal{F}$ Soc Med 1984; 77: 108-10.

23 Manning AP, Wyman JB, Heaton KW. How trustworthy are bowel histories? Comparison of recalled and recorded information. $B M Y$ I 1976; 2: 213-4.

24 Whitehead WE, Drinkwater D, Cheskin LJ, et al. Constipation in the elderly living at home. $7 \mathrm{Am}$ Geriatr Soc 1989; 37: 423-9.

25 Everhart JE, Go VLW, Johannes RS, et al. A longitudinal survey of self reported bowel habits in the United States. Dig Dis Sci 1989; 34: 1153-62.

26 Sonnenberg A, Koch TR. Epidemiology of constipation in the United States. Dis Colon Rectum 1989; 32: 1-8.

27 Sandler RS, Jordan MC, Shelton BJ. Demographic and dietary determinants of constipation in the US population. Am $\mathcal{f}$ Public Health 1990; 80: 185-9.

28 Connell AM, Hilton C, Irvine G, et al. Variation of bowel habit in two population samples. $B M \mathcal{F} 1965$; ii: 1095-9.

29 Heaton KW, Radvan J, Cripps $\mathrm{H}$, et al. Defecation frequency and timing and stool form in the general frequency and timing and stool form in the general

30 Campbell AJ, Busby WJ, Horwath C. Factors associated with constipation in a community based sample of people aged 70 years and over. $\mathcal{F}$ Epidemiol Community Health 1993; 47: 23-6.

31 Edwards RTM, Bransom CJ, Crosby DL, et al. Colorectal carcinoma in the elderly. Age Ageing 1983; 12: 256-62.

2 Curless R, French JM, Williams GV, James OFW. Colorectal carcinoma: do the elderly present differently? Age Ageing (in press).

33 Kemppainen M, Maitra I, Rajala T, et al. Delay in diagnosis of colorectal cancer in elderly patients. Age Ageing 1993; 22: $260-4$. 